Tropical Journal of Pharmaceutical Research October 2016; 15 (10): 2099-2106

ISSN: $1596-5996$ (print); 1596-9827 (electronic)

(C) Pharmacotherapy Group, Faculty of Pharmacy, University of Benin, Benin City, 300001 Nigeria.

All rights reserved.

Available online at http://www.tjpr.org

Original Research Article

http://dx.doi.org/10.4314/tjpr.v15i10.7

\title{
Bioactive content, hepatoprotective and antioxidant activities of whole plant extract of Micromeria fruticosa (L) Druce ssp Serpyllifolia F Lamiaceae against Carbon tetrachloride-induced hepatotoxicity in mice
}

\author{
Eman Abu-Gharbieh ${ }^{1,2 \star}$ and Naglaa G Ahmed ${ }^{3,4}$ \\ ${ }^{1}$ Department of Basic Medical Sciences, College of Medicine-University of Sharjah, Sharjah, United Arab Emirates, \\ ${ }^{2}$ Department of Pharmacology and Toxicology, Dubai Pharmacy College, Dubai, United Arab Emirate, ${ }^{3}$ Department of \\ Pharmaceutical Chemistry and Natural Products, Dubai Pharmacy College, Dubai, United Arab Emirate, ${ }^{4}$ Department of \\ Pharmacognosy, University of Cairo, Egypt.
}

*For correspondence: Email: eabugharbieh@sharjah.ac.ae Tel: +(971) 65057289

Received: 24 May 2016

Revised accepted: 15 September 2016

\begin{abstract}
Purpose: To investigate the antioxidant and hepatoprotective activities of Micromeria fruticosa Druce (L.) Druce ssp Serpyllifolia F. Lamiaceae (MF) extract and to correlate its phenolic composition of the biological activities.

Methods: Reversed-phase high-performance liquid chromatography (RP-HPLC) was employed for the identification and quantification of phenolics. 2,2-Diphenyl-1-picrylhydrazyl (DPPH) radical scavenging potential of the four extracts, namely, ethanol, methanol, acetone, and ethyl acetate, were assessed. The hepatoprotective and antioxidant activities were evaluated against carbon tetrachloride (CCl 4$)$ induced hepatotoxicity in mice. Antioxidant status in the liver was assessed by determining the activities of some antioxidative enzymes, namely, superoxide dismutase (SOD), catalase (CAT) and glutathione peroxidase (GSH-Px), and the levels of thiobarbutaric acid reactive substances (TBARS).

Results: RP-HPLC analysis revealed high contents of quercitrin, rosmarinic and ferulic acid. The four extracts were potent DPPH free radical scavengers. Administration of the ethanol extract to the animals twice daily for 14 days did not show any evidence of hepatotoxicity. $\mathrm{CCl}_{4}$ caused a marked increase in TBARS and significant decrease in CAT, GSH-Px and SOD levels, but this was reversed by the ethanol extract.

Conclusion: The ethanol extract of Micromeria fruticosa $(L)$ may have a palliative effect in liver injuries and this is probably due to the antioxidant properties of the plant's polyphenolic content.
\end{abstract}

Keywords: Micromeria fruticose, Phenolics, Hepatotoxic, Hepatoprotective, Antioxidant, Quercitrin, Ferulic acid, Rosmarinic acid

Tropical Journal of Pharmaceutical Research is indexed by Science Citation Index (SciSearch), Scopus, International Pharmaceutical Abstract, Chemical Abstracts, Embase, Index Copernicus, EBSCO, African Index Medicus, JournalSeek, Journal Citation Reports/Science Edition, Directory of Open Access Journals (DOAJ), African Journal Online, Bioline International, Open-J-Gate and Pharmacy Abstracts

\section{INTRODUCTION}

Phenolics are plant metabolites with well-known protective action against various health diseases [1]. For instance, they possess numerous biological activities e.g. anti-inflammatory [2], anti-diabetic [3], antioxidant, cytotoxic and antitumor $[4,5]$.

Micromeria fruticosa Druce (Wildflowers, White Micromeria) is used widely in many Mediterranean countries as herbal infusion for various inflammatory conditions and in wound 
healing [6]. It is a member of genus Micromeria and is known as zutalevana and ashab a-shai in Hebrew and Arabic respectively. The essential oil of Micromeria fruticosa (MF) is comprised largely of monoterpenes (+)-pulegone and isomenthol $[7 ; 8]$. The aqueous extract of the plant is reported to possess anti-inflammatory [6;7], analgesic [8] and gastroprotective activities [6]. Also, the aqueous extract and the volatile oil exhibited marked antitumor activities against human colon tumor cells and mammary carcinoma F7 [8]. Toxicity study of its aqueous extract was reported previously on mice and it was safe up to $5 \mathrm{~g} / \mathrm{kg}[8]$.

The current study aimed to evaluate the possible hepatoprotective and antioxidant activities of the ethanol extract of Micromeria fruticosa, and to determine if there is a correlation between its phenolic composition and biological activities.

\section{EXPERIMENTAL}

\section{Chemicals and drugs}

Chloroform, ethanol, methanol, acetone, and ethyl acetate were purchased from Fisher Scientific, USA. Carbon tetrachloride $\left(\mathrm{CCl}_{4}\right), 2,2-$ diphenyl-1-picrylhydrazyl (DPPH), sodium carboxymethylcellulose (CMC), biochemical kits for determination of glutathione peroxidase (GPx), superoxide dismutase (SOD), catalase (CAT) and thiobarbituric acid reactive substances (TBARS) were purchased from Sigma Chemical Co. (St. Louis, MO, USA). Folin-Ciocalteu reagent was obtained from Merck (Darmstadt, Germany). All other chemicals were of analytical grade.

\section{Plant material}

The whole plant of Micromeria fruticosa was collected in July 2012 from Nablus, Palestine. In August 2012, the sample was identified and authenticated by Dr. Hassnaa Ahmed Hosny, Professor of Plant Taxonomy, Department of Botany, Faculty of Science, Cairo University, Egypt. Voucher specimen was kept at the Herbarium of Dubai Pharmacy College, Dubai, UAE. Sample, air-dried in shade, powdered and preserved for the current study.

\section{Experimental animals}

Thirty healthy male albino mice ( $30-35 \mathrm{~g}$ ) were used. The animals were kept under the same standard conditions (temperature $22.0 \pm 2.0^{\circ} \mathrm{C}$, relative humidity $50-60 \%$, with $12 \mathrm{~h}$ day/night light cycle), fed with well-balanced normal diet purchased from LabDiet $₫$ and water supplied ad libitum. All mice were acclimated for one week before commencing the experiments. All the animals were treated according to the Guide for the Care and Use of Laboratory Animals published by the US National Institutes of Health [9]. The experimental procedures were approved by the Research Ethical Committee of the Dubai Pharmacy College, Dubai, United Arab Emirates (ref no.14-11-2012)

\section{Plant extract preparation}

The air-dried powdered plant material $(1 \mathrm{~kg})$ was exhaustively extracted twice by cold maceration in five liters of $70 \%$ ethanol. The solvent was evaporated under reduced pressure at $50{ }^{\circ} \mathrm{C}$ to yield $200 \mathrm{~g}$ dry residue. The dried extract was kept in a refrigerator and used for biological evaluation study.

\section{Assay of phenolic content}

Solvents of different polarities, namely $70 \%$ ethanol, methanol, acetone and ethyl acetate, were individually used for extraction of the airdried powdered plant material (100 g each) through cold maceration. The solvents were separately evaporated under reduced pressure at $50{ }^{\circ} \mathrm{C}$. Total phenolic and flavonoid contents were colorimetrically estimated by spectrophotometer (UV-1700 Pharma Spec, Shimadzu, Japan). The experiments were carried out in triplicate.

Total phenolic content was assessed by FolinCiocalteu method described by Oktay et al [11]. Results were expressed in $\mathrm{mg} / \mathrm{g}$ gallic acid equivalent, calculated on dry weight of plant material; serial dilutions of gallic acid $(10,20,30$, 40 and $50 \mu \mathrm{g} / \mathrm{mL}$ ) were used for establishment of the calibration curve.

Aliquot (1 $\mathrm{mL}$ each) of test samples and standard was, separately, added to $9 \mathrm{~mL}$ of water in a volumetric flask followed by $1 \mathrm{~mL}$ of FolinCiocalteu reagent. Furthermore, the reaction mixture was vortexed and left to stand for $5 \mathrm{~min}$. Thereafter, $10 \mathrm{~mL}$ of $7 \%$ sodium carbonate was added and the mixture was incubated for $90 \mathrm{~min}$, at room temperature. Finally, the absorbance was measured at $750 \mathrm{~nm}$ against the reagent blank.

Total flavonoid content of the extract was measured spectrophotometrically by the aluminum chloride method, using quercetin as standard [12]. Plant extracts ( $0.1 \mathrm{~mL}$ each) were mixed individually with $0.3 \mathrm{~mL}$ distilled water and $0.03 \mathrm{~mL}$ of $5 \%$ sodium nitrite. The reaction 
mixture was left for $5 \mathrm{~min}$, at $25 \circ \mathrm{C}$. Aluminum chloride solution $(0.03 \mathrm{~mL}, 10 \%)$ was added, and the mixture left for another $5 \mathrm{~min}$. Later, $\mathrm{NaOH}$ solution $(0.2 \mathrm{~mL}, 1 \mathrm{mM})$ was added to the mixture, and diluted with distilled water up to 1 $\mathrm{mL}$. Absorbance was measured at $510 \mathrm{~nm}$.

\section{RP-HPLC analysis of phenolics}

The phenolic composition of the methanol extract of MF was investigated in aliquots $(1 \mathrm{~g}$, ) with RPHPLC on a Hewlett Packard HPLC System (HP 1050 HPLCDADw/Data System). Analyses were carried out at operating conditions suitable for detection of both phenolic acids and flavonoids [13;14]. For determination of phenolic acids, the apparatus was equipped with an Alltima C18 column (particle size $5 \mathrm{~mm}, 150 \times 4.6 \mathrm{~mm}$ ) and Alltima C18 guard column (5 mm) (Alltech, USA), the UV detector being set at $280 \mathrm{~nm}$. In addition, the separation of flavonoids was carried out on a Hypersil-ODS C18 column (particle size $5 \mu \mathrm{m}$, $4.6 \times 250 \mathrm{~mm}$ ) and the UV detector was set at $330 \mathrm{~nm}$. All analyses were performed at $35{ }^{\circ} \mathrm{C}$; gradient elution was employed using acetonitrileacetic acid mixtures as mobile phase, at a flow rate of $1 \mathrm{~mL} / \mathrm{min}$, and the injection volume was $10 \mu \mathrm{L}$ for both standard and test samples. Authentic reference samples were prepared by diluting stock solutions with methanol to prepare a final concentration of $50 \mu \mathrm{g} / \mathrm{mL}$. Identification of individual components was performed by comparing their retention times with those of the available standards similarly analyzed. Quantification was based on peak area computation using the external standard method. All analyses were carried out in triplicate and the results were recorded as mean.

\section{2, 2-Diphenyl-1-picrylhydrazyl (DPPH) radical scavenging assay}

Different solvents were used for the extraction of MF namely, $70 \%$ ethanol, methanol, acetone, and ethyl acetate. All the extracts were tested in vitro for their abilities to scavenge the free radicals by using the stable DPPH radical. The assay was performed in a 96-well microtiter plate using a previously described method [15].

A percentage inhibition (\%) of the DPPH radical by the samples was calculated using Eq 1.

Inhibition $(\%)=\left\{A_{0}-\left(A_{1}-A_{2}\right) / A_{0}\right\} \times 100$

where $A_{0}$ is the absorbance of the control, $A_{1}$ is the absorbance in the presence of the sample and $A_{2}$ is the absorbance of the sample under identical conditions as $A_{1}$ with ethanol instead of $\mathrm{DPPH}$ solution. Ascorbic acid (AA) was used as a reference compound. $\mathrm{IC}_{50}$ values were calculated. Samples were analyzed in triplicate.

\section{Evaluation of hepatoprotective effect}

The rats were randomly assigned to five groups of 6 animals each. The residue of ethanolic extract was suspended in $1 \%$ CMC.

Group I: served as normal control and received the vehicle orally ( $1 \%$ CMC) during the experiment period. Group II: served as a hepatotoxicity control group, and animals received $1 \%$ CMC solution orally for 14 days. Three groups were devoted for MF extract treatment; group III: received the plant extract orally twice daily at a dose of $200 \mathrm{mg} / \mathrm{kg}$ for 14 days to assess the possible hepatotoxicity that may arise from by the plant itself. Groups IV and $V$ were used to evaluate the possible hepatoprotective activity of the plant extract. Thus, animals were pre-treated with the extract for 14 days in two different doses (100 and 200 $\mathrm{mg} / \mathrm{kg}$ ) respectively. After a 14-day treatment, hepatic injury was induced by intraperitoneal injection of $1.0 \mathrm{ml} / \mathrm{kg}$ of $\mathrm{CCl}_{4}$ in groups II, IV and $\mathrm{V}$ and the mice were sacrificed six hours after the last treatment by ether anesthesia.

\section{Liver enzyme assessment}

Blood samples were collected from the animals' hearts individually with the use of $3 \mathrm{ml}$ sterile syringe and blood was transferred immediately into non-heparinized tubes and used later for the analyses of liver enzymes: alanine aminotransferase (ALT), aspartate aminotransferase (AST) and alkaline phosphatase (ALP).

\section{Assay of antioxidant enzymes in liver homogenate}

Liver samples were removed surgically from the mice immediately and kept in $-80{ }^{\circ} \mathrm{C}$ in So-Low Ultra Low Upright Freezer for further antioxidant enzyme assay. The activity of catalase, superoxide dismutase, glutathione peroxidase and TBARS was assessed as per the method described by Abu-Gharbieh et al [16].

\section{Histopathological examination}

Samples from the liver were suspended in $10 \%$ formaldehyde for further histological assessment. Liver tissue was processed and embedded in paraffin wax. Sections of $5 \mu \mathrm{m}$ in thickness were cut and stained with hematoxylin and eosin $(\mathrm{H}$ \& E) stain and assessed under a light microscope (CH20-Olympus®). 


\section{Statistical analysis}

The data are reported as mean \pm standard deviation ( $S D, n=3$ ). The data were analyzed using one-way analysis of variance (ANOVA), followed by Dunnett's multiple comparison test (DMCT). $P<0.05$ was considered statistically significant.

\section{RESULTS}

Influence of extracting solvent on total phenolic and flavonoid contents

All the tested extracts were found to be rich in both phenolic acids as well as flavonoids compounds as shown in Table 1. The highest amount of flavonoids was detected in the methanolic extract $(2.66 \%)$ followed by ethanolic extract $(1.01 \%)$. Ethyl acetate and acetone extracts showed flavonoid content of 0.55 and $0.22 \%$ respectively. On the other hand, all the tested extracts showed approximately similar content of phenolic acids calculated as $\mathrm{mg} / \mathrm{g}$ gallic acid.

\section{Phenolic content}

A total of 13 components (corresponding to $22.83 \%$ of the total composition) were identified at $280 \mathrm{~nm}$ as shown in Table 2. Among them, eight phenolic acids were identified (13.69\%) with prevalence of ferulic acid (4.30 \%). Moreover, two flavonoids, catechin and chrysin, and a diphenol compound, namely catechol were detected. A non-phenolic compound, benzoic acid, was present in a high concentration (2.08 $\%)$. On the other hand, by setting the detector at $\lambda=330 \mathrm{~nm}$, six compounds were identified
(Table 2). Among them, five were flavonoids with major quercitrin (4.72 \%). Moreover, rosmarinic acid (phenolic acid) was detected in a high amount (4.23\%).

Table 2: Phenolic constituents of the methanol extract of $M$. fruticose

\begin{tabular}{ll}
\hline$\lambda=\mathbf{2 8 0} \mathbf{n m}$ & $\lambda=\mathbf{3 3 0} \mathbf{n m}$ \\
\hline Pyrogallol & Quercetin \\
Gallic acid & Rosmarinic acid \\
Protocatechuic acid & Rutin \\
Catechin & Quercitrin \\
Chlorogenic acid & Kampferol \\
Catechol & Apigenin \\
Vanillic acid & \\
Ferulic acid & \\
Ellagic acid & \\
Benzoic acid & \\
Coumaric acid & \\
Cinnamic acid & \\
Chrysin & \\
\hline
\end{tabular}

Compound identified using HPLC at $\lambda=280$ and 330 $n m$

\section{DPPH free radical scavenging activity}

The four MF extracts were found to be potent $\mathrm{DPPH}$ radical scavengers comparable to the ascorbic acid as shown in Figure 1. No statistical differences were found between the tested extract groups and the reference $(p<0.05)$.

\section{Serum markers of liver damage}

Injection of carbon tetrachloride induced a significant increase of ALT and AST by six and two folds respectively compared to control group $(p<0.01)$, while ALP was not significantly affected as shown in Table 3.

Table 1: Total flavonoid and phenolic acid contents $(n=3)$ of $M$. fruticosa extracts

\begin{tabular}{|c|c|c|c|}
\hline Methanol extract & Ethanol extract & Acetone extract & Ethyl acetate extract \\
\hline \multicolumn{4}{|c|}{ Total flavonoid content (g quercetin/100g) } \\
\hline $2.66 \pm 0.01$ & $1.01 \pm 0.02$ & $0.55 \pm 0.04$ & $0.22 \pm 0.01$ \\
\hline $\begin{array}{c}\text { Total phenolic co } \\
4.01 \pm 0.10\end{array}$ & $\begin{array}{r}\text { tent } \mathbf{m g ~ G A E} / \mathbf{g} \\
3.92 \pm 0.06\end{array}$ & $3.74 \pm 0.03$ & $3.91 \pm 0.02$ \\
\hline
\end{tabular}




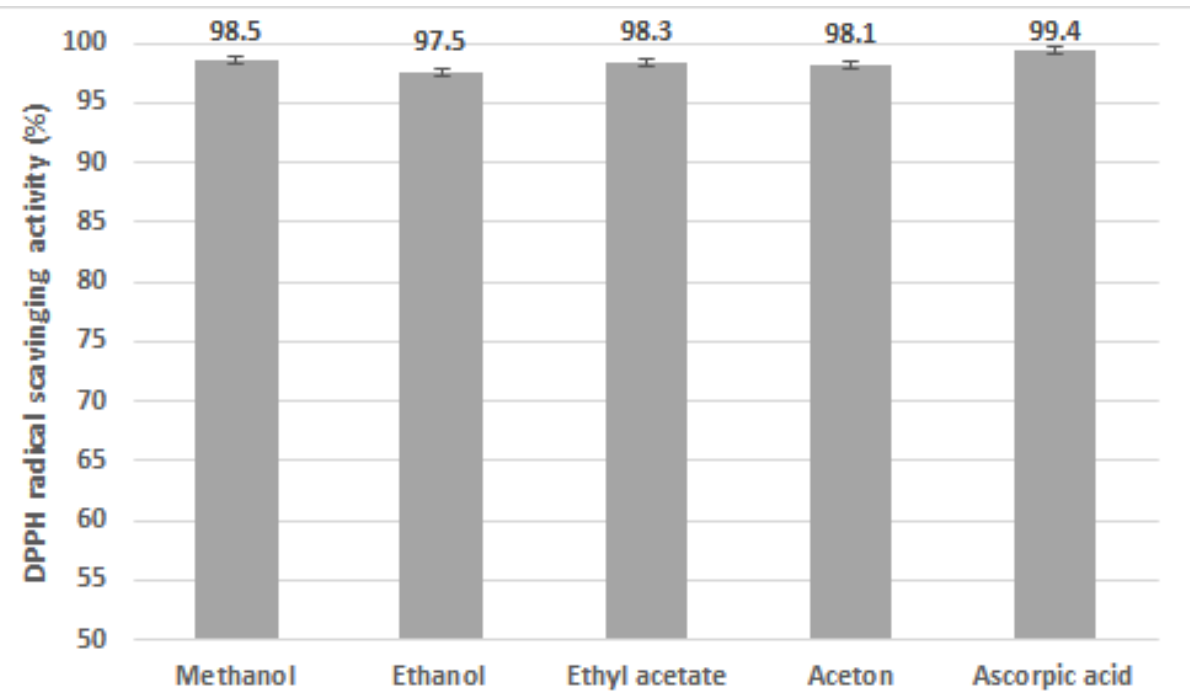

Figure 1: DPPH radical scavenging activity of the plant extracts in different solvents $(p<0.05, \mathrm{n}=3)$

Table 3: Effect of plant extracts on biochemical profile of mice

\begin{tabular}{|c|c|c|c|c|c|}
\hline \multirow[t]{2}{*}{ Animal group } & \multicolumn{5}{|c|}{ Group } \\
\hline & $I$ & II & III & IV & $\mathbf{V}$ \\
\hline$\overline{A L T}$ & $290.1 \pm 54.0$ & $1736.7 \pm 161.2^{b}$ & $395.3 \pm 32.9$ & $1010.3 \pm 223.3^{d}$ & $604.3 \pm 154.2^{d}$ \\
\hline AST & $850.0 \pm 63.2$ & $1736.7 \pm 215.1^{\mathrm{b}}$ & $614.2 \pm 37.2$ & $849.5 \pm 112.9^{d}$ & $789.3 \pm 65.6^{d}$ \\
\hline ALP & $180.0 \pm 20.3$ & $150.2 \pm 55.7$ & $58.8 \pm 5.3^{d}$ & $78.0 \pm 8.2^{d}$ & $59.8 \pm 8.6^{d}$ \\
\hline CAT kU/g protein & $462.0 \pm 21.1$ & $241.3 \pm 11.4^{\mathrm{D}}$ & $504.1 \pm 6.1$ & $366.9 \pm 22.7^{a}$ & $408.5 \pm 12.7^{a}$ \\
\hline GSH-Px U/g protein & $1.3 \pm 0.1$ & $0.9 \pm 0.1^{a}$ & $1.4 \pm 0.1$ & $1.0 \pm 0.2$ & $1.2 \pm 0.1$ \\
\hline SOD $\mu \mathrm{g} / \mathrm{g}$ protein & $34.6 \pm 2.9$ & $22.0 \pm 2.4^{\mathrm{D}}$ & $35.9 \pm 3.3$ & $30.5 \pm 1.3^{c}$ & $34.8 \pm 1.5^{\mathrm{a}}$ \\
\hline TBARS (nmol/g & $0.05 \pm 0.02$ & $0.5 \pm 0.2^{b}$ & $0.1 \pm 0.1$ & $0.2 \pm 0.1^{d}$ & $0.1 \pm 0.0^{\mathrm{d}}$ \\
\hline
\end{tabular}

${ }^{\mathrm{a}} p<0.05$ compared to group I; ${ }^{\mathrm{b}} p<0.01$ compared to compared to group I; ${ }^{c} p<0.05$ compared to group II; and ${ }^{d}$ $p<0.01$, compared to group II

Administration of MF extract twice daily over two weeks did not show any evidence of hepatotoxicity, as serum ALT and AST levels did not significantly change (Table 3). A significant reduction in ALP level was noticed.

Injecting carbon tetrachloride to the animals pretreated with the plant extract at two different doses (100 and $200 \mathrm{mg} / \mathrm{kg}$ ) resulted in elevation of both ALT and AST levels in serum, this elevation was significantly lower than that caused by $\mathrm{CCl}_{4}$ alone. Noticeable effect occurred in a dose dependent manner since the p-values were less than 0.05 and 0.01 for the 100 and $200 \mathrm{mg} / \mathrm{kg}$ respectively compared to group II. Furthermore, ALP level was reduced significantly in MF treated mice.

\section{Histopathological findings}

Histopathological analysis revealed a dense periportal and lobular lymphocytic infiltrate with diffused pyknotic nuclei within necrotic hepatocytes in periportal areas in the liver tissue obtained from the control group treated with $\mathrm{CCl}_{4}$ alone (Figure 2A). On the other hand, gross hepatocyte renewal and regeneration were observed after the administrating the MF extract twice daily for two consecutive weeks as shown in Figures 2B. Furthermore, pretreating the animals with the plant extract at two different doses improved the histoarchitecture of the hepatic tissue in a dose dependent manner as shown in Figures $2 \mathrm{C}$ and $\mathrm{D}$.

\section{Effect of MF on antioxidant enzymes and TBARS contents}

Administration of $\mathrm{CCl}_{4}$ markedly depleted the antioxidant enzymes (CAT, GSH-Px and SOD) in the mice livers (Table 3$)$. Nevertheless, $\mathrm{CCl}_{4}$ increased significantly $(\mathrm{p}<0.01)$ the hepatic lipid peroxidation that is expressed by high TBARS content. 
Giving the plant extract twice daily for two weeks showed slight enhancement of the antioxidant enzymes and mild reduction in the TBARS
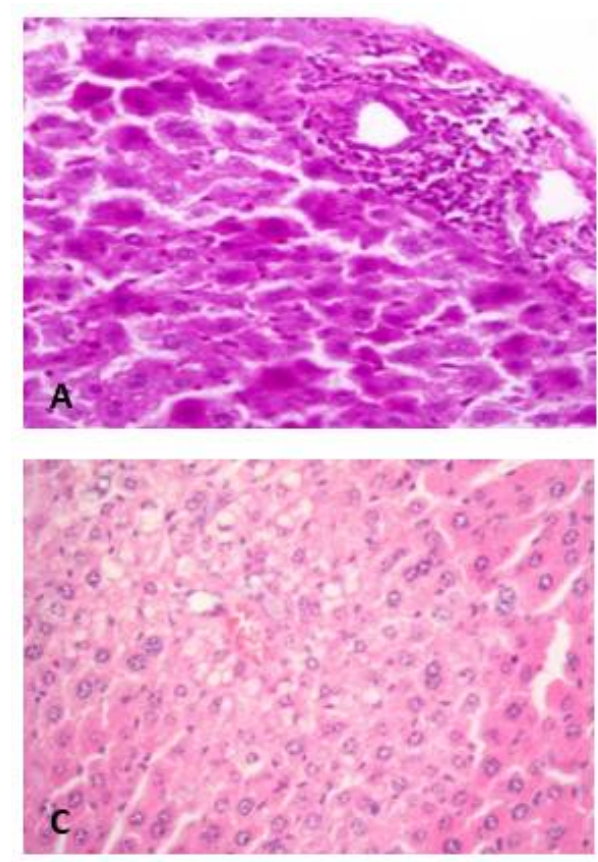
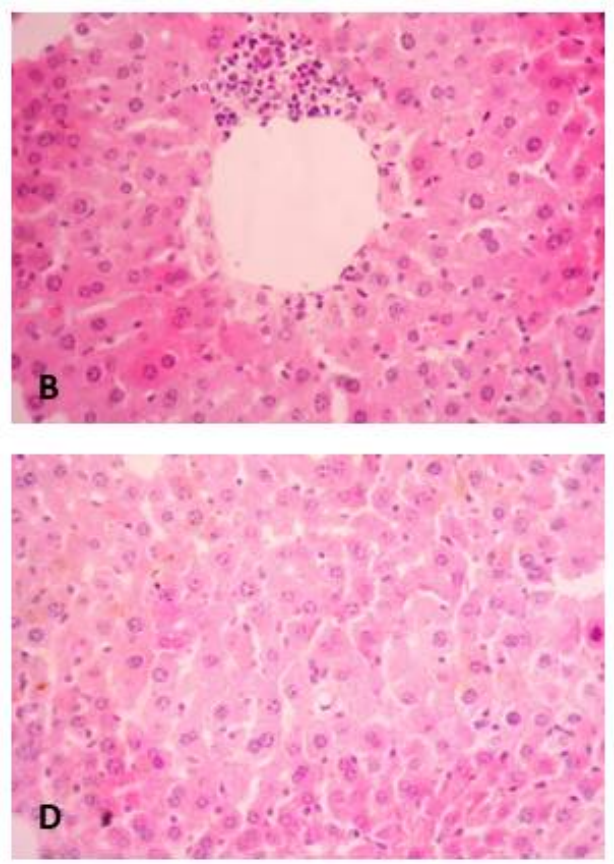

Figure 2: Histopathological findings of mice liver sections under light microscope $(H \& E x 400)$; (A) Control group treated with $\mathrm{CCl}_{4}$, showing marked periportal and lobular lymphocytic infiltration with pyknotic nuclei within necrotic hepatocytes; (B) treated with $200 \mathrm{mg} / \mathrm{kg} \mathrm{MF}$ twice daily showing normal regenerating hepatocytes; (C) treated with $100 \mathrm{mg} / \mathrm{kg} \mathrm{MF}$ and $\mathrm{CCl}_{4}$ showing focal area of hepatocytes vacuolar degeneration ; (D) treated with $200 \mathrm{mg} / \mathrm{kg} \mathrm{MF}$ and $\mathrm{CCl}_{4}$ showing marked improvement in the histoarchitecture of the hepatic tissue

content, but they were all statistically insignificant as shown in Table 3.

Pretreating the mice with the plant extract at different doses reversed significantly the reduction in catalase and superoxide dismutase levels caused by $\mathrm{CCl}_{4}$. On the other hand, the highest dose increased the glutathione peroxidase level but this increment was statistically insignificant. Moreover, MF treatment, at both doses, was effective in inhibiting the hepatic lipid peroxidation, represented by the TBARS content.

\section{DISCUSSION}

Liver is the main organ involved in generation of reactive oxygen species (ROS) induced by various drugs and chemicals [19]. It is wellknown that hepatotoxicity involves induction of oxidative stress due to excessive formation of ROS which causes extensive lipid peroxidation of the hepatocyte cellular membranes [20,21].

Various medicinal plants with long and wellestablished traditional uses have been recommended to treat several hepatic disorders
[22]. Yet, clinical application of those plants needs extensive in vivo pharmacological and toxicological characterization, in addition to extensive clinical studies to explore their usefulness in such diseases.

ALT is found predominately in the liver, with lesser quantities found in the kidneys, heart, and skeletal muscle. As a result, the ALT is a more specific indicator of liver inflammation than AST, as AST may also be elevated in diseases affecting other organs, such as the heart or muscles. Elevation of the alkaline phosphatase level is usually associated with cholestatic liver diseases [23].

Micromeria fruticosa is used widely in many Mediterranean countries for its traditionally known health benefits. It is used commonly to heal wounds and in various inflammatory conditions [6]. In literatures, the aqueous extract of Micromeria fruticosa is reported to show many pharmacological actions such as antiinflammatory [6;7], analgesic [8] and gastroprotective activities [6].

Although the plant extract was not previously 
investigated for its bioactive components, its oil was analysed and it was found to contain high amount of oxygenated compounds [8]. The present study investigated the bioactive components of the plant extract, especially phenolics. Phenolics are considered the medicinal treasure for any plant, since they possess various biological activities such as antiinflammatory, antidiabetic, anticancer and antioxidant [2-5].

Quantitative determination of total phenolics revealed that all extracts were rich in phenolic acids and flavonoids, but the highest amount of flavonoids was present in the methanol extract followed by ethanol extract.

DPPH assay was applied as in vitro approach to assess the free radical-scavenging activity and to screen for the possible antioxidant activity of the different plant extracts. The assay showed that all plant extracts had strong DPPH radical scavenging activity comparable to those of ascorbic acid regardless the type of the extraction solvent. However, for safety, availability and economic concerns, the ethanol extract was selected for the biological study.

Dose selection for the subsequent biological study for the plant extract was done based on its $L D_{50}$ value (less than $1 / 10$ of $L D_{50}$ ). Moreover, similar doses of Micromeria fruticosa were tested previously for its anti-inflammatory, gastroprotective [6] and analgesic [8] activities.

Administration of the plant extract for two weeks enhanced hepatic regeneration and maintained normal liver function. Furthermore, possibility of cholestasis was ruled out since ALP level remained low [24].

The hepatoprotective effect of MF extract had been evaluated on carbon tetrachloride induced hepatotoxicity model in mice. The data showed that injecting the animals with $\mathrm{CCl}_{4}$ resulted in severe liver damage evidenced by sharp increase in hepatic lipid peroxidation and both ALT and AST. Moreover, administration of $\mathrm{CCl}_{4}$ to the animals caused extensive hepatic oxidative stress that is characterized by significant decrease in CAT, GSH-Px and SOD enzymes levels and increase of TBARS content in liver tissue. Furthermore, histopathological assay revealed severe structural loss of hepatic tissue distinctive by dense periportal and lobular lymphocytic infiltrate with diffused pyknotic nuclei within necrotic hepatocytes.

Pre-treating the animals with MF extract for two weeks at two different doses (100 and 200 $\mathrm{mg} / \mathrm{kg}$ ) reduced the intensity of liver damage induced by carbon tetrachloride. ALT and AST levels were also elevated following $\mathrm{CCl}_{4}$ administration. This elevation was significantly less than that caused by $\mathrm{CCl}_{4}$ alone. ALP serum concentration continued to be low in all plant treated groups, that role out cholestasis. Furthermore, the extract reduced significantly the oxidative stress induced by $\mathrm{CCl}_{4}$ and it enhanced the hepatic antioxidant defense system that is represented by CAT, GSH-PX and SOD enzymes and was highly efficient in reducing TBARS content in liver tissue in a dose related manner.

These findings were supported by the histological results since it showed that all harmful effects of carbon tetrachloride on liver tissues were attenuated and tissue architecture was maintained by pretreating the animals with the plant extract in a dose-dependent manner. HPLC analysis revealed that rutin and quercetrin were the main flavonoidal glycosidal compounds present in MF extract. Those flavonoids which contain sugar moiety are most likely hydrolyzed to their aglycones after their oral administration by bacterial intestinal enzymes to quercitin [25] and then absorbed into the intestinal cells by passive mechanisms.

Quercitin has been extensively documented in literature to process high antioxidant activity. Due to this metabolic process of the glycosides, quercitin content available in the intestine appears to be much higher than that present in HPLC data. Accordingly, the hepatoprotective effect of the plant extract could be related to the higher content of different groups of phenolic compounds including flavonoids and phenolic acids that have been earlier reported to exhibit strong antioxidant and hepatoprotective effects.

\section{CONCLUSION}

Micromeria fruticosa extract effectively protects against the hepatotoxicity induced by $\mathrm{CCl}_{4}$ through scavenging of free radicals in mice as well as by boosting the antioxidant capacity of the liver, probably by the bioactive antioxidant principles present in the extract. Therefore, the plant is a potential safe source of protective agents against liver damage.

\section{DECLARATIONS}

\section{Acknowledgement}

This project was funded by Medical Research Fund-Dubai Medical College. The authors wish 
to thank Professor Gehan Gamil Shehab for help with histopathological investigation.

\section{Conflict of Interest}

No conflict of interest associated with this work.

\section{Contribution of Authors}

The authors declare that this work was done by the authors named in this article and all liabilities pertaining to claims relating to the content of this article will be borne by them.

\section{REFERENCES}

1. Hung $T M, N a M$, Thuong $P T$, Su ND, Sok D, Song $K S$, Seong $\mathrm{YH}$, Bae K. Antioxidant activity of caffeoyl quinic acid derivatives from the roots of Dipsacus asper Wall. $J$ Ethnopharmacol 2006; 108: 188-192.

2. Lee S, Son $K$, Chang H, Do J, Jung K, Kang S, Kim H. Antiinflammatory activity of naturally occurring flavone and flavonol glycosides. Arch Pharm Res 1993; 16: 2528.

3. Vessal M, Hemmati M, Vasei M. Antidiabetic effects of quercetin in streptozocin-induced diabetic rats. Comp Biochem Physiol C Toxicol Pharmacol 2003; 135C: 357364.

4. Vivian Cody, Elliott Middleton, Jeffrey B Harborne. Plant flavonoids in biology and medicine. Biochemical, pharmacological, and structure-activity relationships. Proceedings of a symposium. Buffalo, New York, July 22-26, 1985. In 1985.

5. Shaikh $R$, Pund M, Dawane A, lliyas S. Evaluation of Anticancer, Antioxidant, and Possible Anti-inflammatory Properties of Selected Medicinal Plants Used in Indian Traditional Medication. J Tradit Complement Med 2014; 4: 253-257.

6. Abu-Gharbieh E, Shehab NG, Khan SA. Antiinflammatory and gastroprotective activities of the aqueous extract of Micromeria fruticosa (L.) Druce ssp Serpyllifolia in mice. Pak J Pharm Sci 2013; 26: 799803.

7. Abu-Gharbieh E, Bustanji Y, Mohammad M. In vitro effects of Micromeria fruticosa on human leukocyte myeloperoxidase activity. JPR Solutions 2010; 3: 24922493.

8. Shehab NG, Abu-Gharbieh E. Constituents and biological activity of essential oil and aqueous extract of Micromeria fruticosa I druce M. Serpyllifolia. Pak J Pharm Sci 2012; 25.

9. National Research Council (US) Committee for the Update of the Guide for the Care and Use of Laboratory Animals. Guide for the Care and Use of Laboratory Animals, 8th ed. Washington (DC): National Academies Press (US); 2011
10. Singleton VL, Rossi JA. Colorimetry of Total Phenolics with Phosphomolybdic-Phosphotungstic Acid Reagents. AJEV 1965; 16: 144-158.

11. Oktay M, Gulcin I, Kufrevioglu OI. Determination of in vitro antioxidant activity of fennel (Foeniculum vulgare) seed extracts. LWT - Food Sci Technol 2003; 36: 263271.

12. Dewanto $V$, Wu $X$, Adom KK, Liu RH. Thermal processing enhances the nutritional value of tomatoes by increasing total antioxidant activity. J Agric Food Chem 2002; 50: 3010-3014.

13. Goupy P, Hugues M, Boivin P, Amiot MJ. Antioxidant composition and activity of barley (Hordeum vulgare) and malt extracts and of isolated phenolic compounds. $J$ Sci Food Agric 1999; 79: 1625-1634.

14. Mattila $P$, Astola J, Kumpulainen J. Determination of Flavonoids in Plant Material by HPLC with Diode-Array and Electro-Array Detections. J Agric Food Chem 2000; 48: $5834-5841$

15. Cheng Z, Moore J, Yu L. High-throughput relative DPPH radical scavenging capacity assay. J Agric Food Chem 2006; 54: 7429-7436.

16. Abu-Gharbieh E, Bayoumi FA, Ahmed NG. Alleviation of antioxidant defense system by ozonized olive oil in DNBS-induced colitis in rats. Mediat Inflamm 2014; 2014: 967205

17. Lowry Oh, Rosebrough Nj, Farr Al, Randall Aj. Protein measurement with the Folin phenol reagent. $J$ Biol Chem 1951; 193: 265-275.

18. Webster D, Bignell AH, Attwood EC. An assessment of the suitability of bromocresol green for the determination of serum albumin. Clin Chim Acta 1974; 53: 101-108.

19. Alric L, Orfila C, Carrere N, Beraud M, Carrera G, Lepert JC, Duffaut M, Pipy $B$, Vinel JP. Reactive oxygen intermediates and eicosanoid production by kupffer cells and infiltrated macrophages in acute and chronic liver injury induced in rats by CC14. Inflamm Res 2000; 49: 700-707.

20. Weijl NI, Cleton FJ, Osanto S. Free radicals and antioxidants in chemotherapy-induced toxicity. Cancer Treat Rev 1997; 23: 209-240.

21. Bhatia K, Kaur M, Atif F, Ali M, Rehman H, Rahman S, Raisuddin S. Aqueous extract of Trigonella foenumgraecum L. ameliorates additive urotoxicity of buthionine sulfoximine and cyclophosphamide in mice. Food Chem Toxicol 2006; 44: 1744-1750.

22. Chan CP, Ho JW, Leung YK. Potential of medicinal herbs in the treatment of liver disorders. Trends Comp Biochem Physiol 2002; 9: 269-272.

23. Jensen JE, Stainberg SE, Freese $P$, Marino E. Liver function tests. J Digest Disord 2004; 6: 1-3.

24. Johnston DE. Special considerations in interpreting liver function tests. Am Fam Physician 1999; 59: 2223-2230.

25. Hollman PC, Bijsman MN, van GY, Cnossen EP, de Vries $\mathrm{JH}$, Katan MB. The sugar moiety is a major determinant of the absorption of dietary flavonoid glycosides in man. Free Radic Res 1999; 31: 569-573. 